Article

\title{
Event-Associated Oxygen Consumption Rate Increases ca. Five-Fold When Interictal Activity Transforms into Seizure-Like Events In Vitro
}

\author{
Karl Schoknecht 1,2,3,+ (D), Nikolaus Berndt ${ }^{4,+}$, Jörg Rösner ${ }^{3}$, Uwe Heinemann ${ }^{3, \ddagger}$, \\ Jens P. Dreier 1,2,5 (D), Richard Kovács ${ }^{6}$ (D), Alon Friedman ${ }^{7,8}$ and Agustin Liotta 3,9,10,*
}

1 Department of Experimental Neurology, Charité-Universitätsmedizin Berlin, Corporate Member of Freie Universität Berlin, Humboldt-Universität zu Berlin, and Berlin Institute of Health, 10117 Berlin, Germany; karl.schoknecht@charite.de (K.S.); jens.dreier@charite.de (J.P.D.)

2 Center for Stroke Research Berlin, Charité-Universitätsmedizin Berlin, Corporate Member of Freie Universität Berlin, Humboldt-Universität zu Berlin, and Berlin Institute of Health, 10117 Berlin, Germany

3 Neuroscience Research Center, Charité-Universitätsmedizin Berlin, Corporate Member of Freie Universität Berlin, Humboldt-Universität zu Berlin, and Berlin Institute of Health, 10117 Berlin, Germany; joerg.roesner@charite.de (J.R.); karl.schoknecht@googlemail.com (U.H.)

4 Institute of Biochemistry, Charité-Universitätsmedizin Berlin, Corporate Member of Freie Universität Berlin, Humboldt-Universität zu Berlin, and Berlin Institute of Health, 10117 Berlin, Germany;

nikolaus.berndt@charite.de

5 Department of Neurology, Charité-Universitätsmedizin Berlin, Corporate Member of Freie Universität Berlin, Humboldt-Universität zu Berlin, and Berlin Institute of Health, 10117 Berlin, Germany

6 Institute for Neurophysiology, Charité-Universitätsmedizin Berlin, Corporate Member of Freie Universität Berlin, Humboldt-Universität zu Berlin, and Berlin Institute of Health, 10117 Berlin, Germany; richard.kovacs@charite.de

7 Department of Medical Neuroscience, Faculty of Medicine, Dalhousie University, Halifax, NS B3H 4R2, Canada; alon.friedman@Dal.Ca

8 Departments of Physiology and Cell Biology, Cognitive and Brain Sciences, Zlotowski Center for Neuroscience, Ben-Gurion University of the Negev, 84105 Beer-Sheva, Israel

9 Department of Anesthesiology and Intensive Care, Charité-Universitätsmedizin Berlin, Corporate member of Freie Universität Berlin, Humboldt-Universität zu Berlin and Berlin Institute of Health, 10117 Berlin, Germany

10 Berlin Institute of Health (BIH), Anna-Louisa-Karsch-Str. 2, 10178 Berlin, Germany

* Correspondence: agustin.liotta@charite.de; Tel.: +49-30-450-528091

+ These authors contributed equally to this work.

$\ddagger$ Uwe Heinemann passed away on 8 September 2016.

Received: 11 August 2017; Accepted: 1 September 2017; Published: 7 September 2017

\begin{abstract}
Neuronal injury due to seizures may result from a mismatch of energy demand and adenosine triphosphate (ATP) synthesis. However, ATP demand and oxygen consumption rates have not been accurately determined, yet, for different patterns of epileptic activity, such as interictal and ictal events. We studied interictal-like and seizure-like epileptiform activity induced by the $\mathrm{GABA}_{\mathrm{A}}$ antagonist bicuculline alone, and with co-application of the M-current blocker XE-991, in rat hippocampal slices. Metabolic changes were investigated based on recording partial oxygen pressure, extracellular potassium concentration, and intracellular flavine adenine dinucleotide (FAD) redox potential. Recorded data were used to calculate oxygen consumption and relative ATP consumption rates, cellular ATP depletion, and changes in $\mathrm{FAD} / \mathrm{FADH}_{2}$ ratio by applying a reactive-diffusion and a two compartment metabolic model. Oxygen-consumption rates were ca. five times higher during seizure activity than interictal activity. Additionally, ATP consumption was higher during seizure activity ( $\sim 94 \%$ above control) than interictal activity ( 15\% above control). Modeling of FAD transients based on partial pressure of oxygen recordings confirmed increased energy demand during both seizure and interictal activity and predicted actual FAD autofluorescence recordings, thereby
\end{abstract}


validating the model. Quantifying metabolic alterations during epileptiform activity has translational relevance as it may help to understand the contribution of energy supply and demand mismatches to seizure-induced injury.

Keywords: epilepsy; oxygen; ATP

\section{Introduction}

Due to its high energy demand, the brain receives about $15 \%$ of the heart stroke volume [1]. Epileptic seizures, i.e., paroxysmal, hypersynchronous, and excessive cell firing, elevate energy consumption due to massive neurotransmitter release and associated energy-dependent neurotransmitter recycling and recovery of ion gradients (largely by the $\mathrm{Na}^{+}-\mathrm{K}^{+}$-ATPase) [2,3]. In addition to seizures (i.e., ictal events,) brief interictal discharges can be observed in the whole cortex or in epileptic foci [4] and may result in local vasodilation suggesting increased energy demand [5]. Ivanov et al. recently described different metabolic "footprints" for ictal and interictal events in the immature mice whole hippocampus preparation-all showing different degrees of elevated metabolism indicated by drops in tissue partial pressure of oxygen $\left(\mathrm{pO}_{2}\right)$ and changes in $\mathrm{NADH} / \mathrm{NAD}^{+}$(nicotinamide adenine dinucleotide) and $\mathrm{FADH}_{2} / \mathrm{FAD}$ (flavine adenine dinucleotide) ratio [6]. Positron emission tomography studies in humans often show ictal hypermetabolism and interictal hypometabolism within epileptic foci related to mitochondrial dysfunction $[7,8]$. Although a mismatch in energy supply and demand during and following epileptic discharges may subsequently lead to injury [9], very little is known on the actual oxygen consumption rates in relation to the energy demand during different forms of epileptic activity.

Here we describe oxygen and ATP consumption rates in two well-characterized types of epileptic activity in the hippocampal area CA3: interictal-like events (ILEs) and seizure-like events (SLEs). ILEs were pharmacologically induced by the gamma aminobutyric acid receptor $A\left(G A B A_{A}-R\right)$ antagonist bicuculline. These short hypersynchronous events, also called recurrent epileptiform discharges [10], are electrophysiologically similar to interictal spikes recorded in vivo. Compared with ILEs, SLEs are typically prolonged and associated with repetitive field potential discharges and greater increases in extracellular potassium $\left(\left[\mathrm{K}^{+}\right]_{\mathrm{o}}\right)[11,12]$. To induce SLEs in the same preparation, we co-applied bicuculline and the M-current blocker XE-991. M-currents are non-inactivating outward potassium currents mediated by Kv7 channels that stabilize the resting membrane potential [13]. Importantly, Kv7 channel mutations were found in epilepsy syndromes [14,15].

To assess cerebral metabolism of ILEs and SLEs, we simultaneously recorded local field potential, $\left(\left[\mathrm{K}^{+}\right]_{\mathrm{o}}\right), \mathrm{pO}_{2}$ and $\mathrm{FAD}$ autofluorescence. Kinetics of $\left[\mathrm{K}^{+}\right]_{\mathrm{o}}$ reflect the ion movements during neuronal de- and repolarization, while changes in tissue $\mathrm{pO}_{2}$-in the absence of blood flow-reflect cellular respiration. As FAD emits fluorescence when excited at $450 \mathrm{~nm}\left(\mathrm{FADH}_{2}\right.$ is non-fluorescent), changes in the autofluorescence $(>515 \mathrm{~nm}$ ) give an indication of the redox changes in the FADH ${ }_{2} /$ FAD couple $[6,16,17]$. Using a model of oxygen transport and consumption within brain slice preparations [18] and measured $\mathrm{pO}_{2}$ depth profiles, we calculated oxygen consumption rates (OCRs) during ILEs and SLEs. Subsequently, ATP consumption rates, intracellular ATP levels and FAD reduction states were calculated from the OCRs by applying a model of neuronal energy metabolism [19]. Model predictions were, in part, validated by comparing computed FAD reduction states with recorded FAD autofluorescence signals.

\section{Results}

\subsection{Properties of Interictal- and Seizure-Like Events in Hippocampal Area CA3}

Two types of epileptiform activity, ILEs and SLEs were recorded in the rat CA3 hippocampal region in the acute slice preparation (Figures 1 and $2 \mathrm{~A}$ ). ILEs were usually recorded within $\sim 40 \mathrm{~min}$ after 
application of bicuculline and were characterized by paroxysmal slow wave discharges. ILEs lasted $0.18 \mathrm{~s}(0.16,0.20$; data shown as median and 25th and 75th percentile in brackets; $n=6)$ and were significantly prolonged by the additional application of XE-991 to $4.3 \mathrm{~s}(4.0,5.3 ; n=6, p<0.05$; Figure 1B). These second long paroxysmal events occurred within 20-40 min following XE-991 application and were considered SLEs. SLEs started with a burst of action potentials (resembling ILEs) followed by a succession of after-discharges (Figure 1C,D) Event amplitudes of $6.3 \mathrm{mV}(4.4,7.9)$ for ILEs were similar to $6.6 \mathrm{mV}(5.0,7.2)$ for SLEs, while the event incidence decreased significantly from 4.9 (3.6, $5.1)$ to 2.4 events $/ \min (1.8,3.0 ; n=6, p<0.05$; Figure $1 \mathrm{~B})$. [ $\left[\mathrm{K}^{+}\right]_{\mathrm{o}}$-rises during SLEs were prolonged and elevated to $7.9 \mathrm{mM}(6.5,9.3 ; n=6, p<0.05$, Figure $1 \mathrm{~A}, \mathrm{~B})$ compared with $4.5 \mathrm{mM}(4.2,5.5$; see Figure $1 \mathrm{~B}$; line-median, dot-mean) during ILEs. Intracellular recordings revealed that CA3 pyramidal cells depolarized by $36.0 \mathrm{mV}(31.4,53.1$; Figure 1G) during SLEs, which is a $24 \%$ increase compared with ILEs that depolarized by $24.9 \mathrm{mV}(21.9,30.0 ; n=11$ cells from six slices, $p<0.05)$. While the number of action potentials (APs) for SLEs decreased during the initial burst (7.7, range 5.8, 11.5 APs /events compared with 20.3, range 17.9, 24.9, for ILEs; $n=11$ cells from six slices, $p<0.05$ ), additional APs were evoked during SLE repetitive after-discharges (median 36.0, 31.4, 53.1 APs/event; $p<0.05$, Figure 1F,G). High-frequency oscillations (HFOs) during ILEs were previously described [10] and typically showed two peaks at $\sim 190$ and $\sim 290 \mathrm{~Hz}$ (Figure 1D,E). Compared with ILEs, HFOs during SLEs showed only one peak with lower frequency $(\sim 180 \mathrm{~Hz}$; Figure 1E).

\subsection{Basal Oxygen Consumption Rates under Bicuculline and Bicuculline Plus XE-991}

To calculate oxygen consumption rates (OCRs), we applied a mathematical reaction-diffusion model [18] to experimentally recorded $\mathrm{pO}_{2}$ depth profiles (Figure 2A). Under interface recording conditions, $\mathrm{pO}_{2}$ was maximal at the slice surface $(\sim 680 \mathrm{mmHg})$ and minimal $(\sim 300 \mathrm{mmHg})$ in the slice core at a depth of $\sim 200 \mu \mathrm{m}$. After trespassing the core, $\mathrm{pO}_{2}$ increased again as oxygen diffused from the bottom via the perfused artificial cerebrospinal fluid (aCSF). Depth profiles were recorded under control conditions (aCSF only) and in the presence of bicuculline (while recording ILEs) or bicuculline $+10 \mu \mathrm{M}$ XE-991 (while recording SLEs; Figure 2B, also see methods). Basal $\mathrm{pO}_{2}$ levels during event-free intervals were used to calculate basal OCRs. Basal OCR slightly increased from $25.1 \mathrm{mmHg} \cdot \mathrm{s}^{-1}$ (22.4, 25.8) under control conditions to $26.2 \mathrm{mmHg} \cdot \mathrm{s}^{-1}(21.2,32.0, n=8)$ under bicuculline. When XE-991 was added to the aCSF, basal OCR significantly increased to $30.9 \mathrm{mmHg} \cdot \mathrm{s}^{-1}(22.6,33.0)$ (Figure 2B inset, line-median, dot-mean, $n=8, p<0.008$, paired $t$-test with Bonferroni post-hoc test).

\subsection{Event-Associated Oxygen Consumption Rates for ILEs and SLEs}

To calculate event-associated OCRs (EAOCRs) we quantified amplitudes of oxygen dips during individual events. Figure $3 \mathrm{~A}$ shows exemplary field potential, $\left[\mathrm{K}^{+}\right]_{\mathrm{o}}$ and $\mathrm{pO}_{2}$ recordings for ILEs (bicuculline) and SLEs (bicuculline + XE-991). Drops in $\mathrm{pO}_{2}$ were significantly larger for SLEs compared with ILEs (median $-31.0 \mathrm{mmHg}$ vs. $-5.0 \mathrm{mmHg}$, SLE: P25 -45.1, P75 -12.9, ILE: P25 - 5.8, P75 $-3.8, n=15$ (SLE) and 8 (ILE) $p=0.011$, Figure 3B). Focal $\mathrm{pO}_{2}$ recordings do not reveal the location of oxygen consumption along the diffusion path between the oxygen source and the electrode location. To estimate locality of activity we measured depth-dependent field potential amplitudes and $\left[\mathrm{K}^{+}\right]_{\mathrm{o}}$-rises (Figure 3C-E). This revealed a bell shape of activity that was maximal at a depth of $\sim 80-100 \mu \mathrm{m}$ from the slice surface while $\mathrm{pO}_{2}$-drops per event increased successively to a depth of $\sim 100 \mu \mathrm{m}$ and remained elevated (no bell shape) towards the core of the slice (i.e., further away from the source of oxygen; Figure 3E). Using the spatial distribution of neuronal activity, while assuming that OCR is proportional to local neuronal activity, we calculated EAOCR for ILEs and SLEs. Figure 3F shows the mean basal OCR and EAOCR for ILEs and SLEs averaged over 8 (ILEs) and 15 (SLEs) slices and 10 events per slice. While ILEs increased local EAOCR by $3 \%$ (in absolute numbers: $0.8 \mathrm{mmHg} \cdot \mathrm{s}^{-1}, 0.7,1.0$ ) compared with basal OCR, SLEs were associated with an increased EAOCR by $18 \%\left(5.2 \mathrm{mmHg} \cdot \mathrm{s}^{-1}, 2.5,10.6\right.$; Figure $3 \mathrm{G}$ ). Compared with control condition EAOCR was elevated by $8 \%$ for ILEs and $44 \%$ for SLEs (Figure 4A, 3rd plot). 

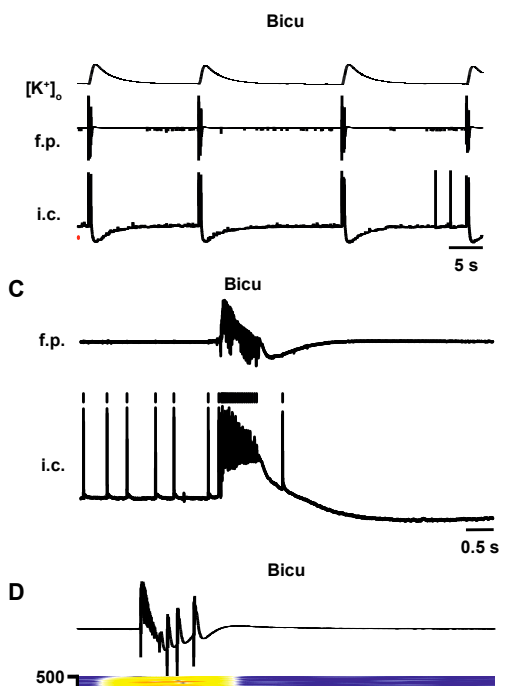

D

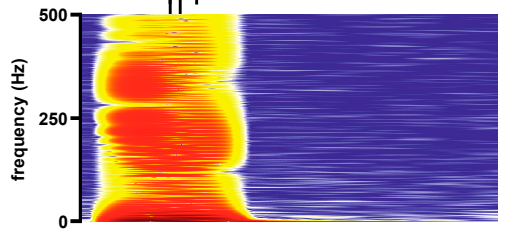

$\overline{0.1 \mathrm{~s}}$

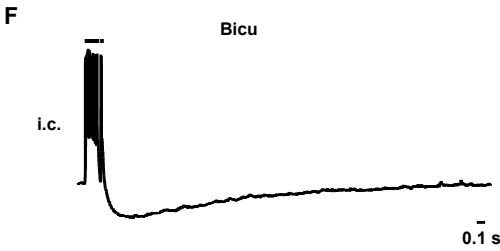

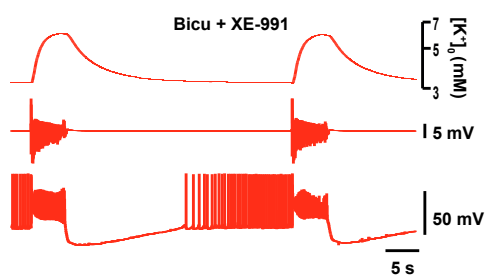
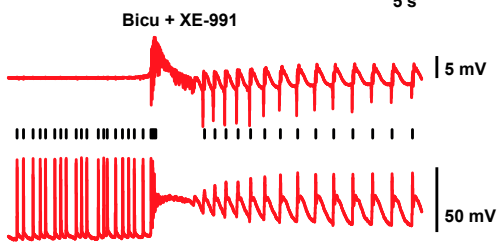

$\overline{0.5 \mathrm{~s}}$

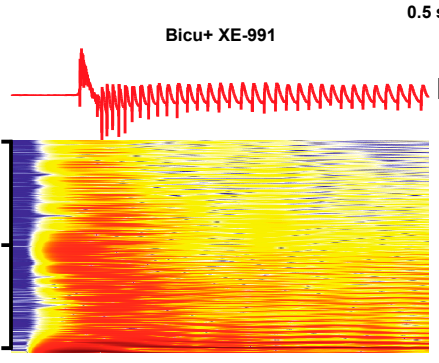

$\overline{0.1 \mathrm{~s}}$

Bicu+ XE-991

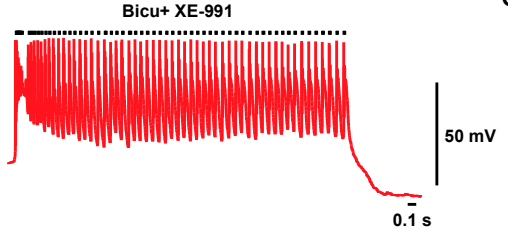

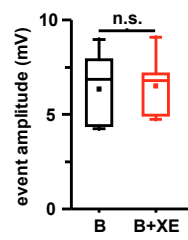
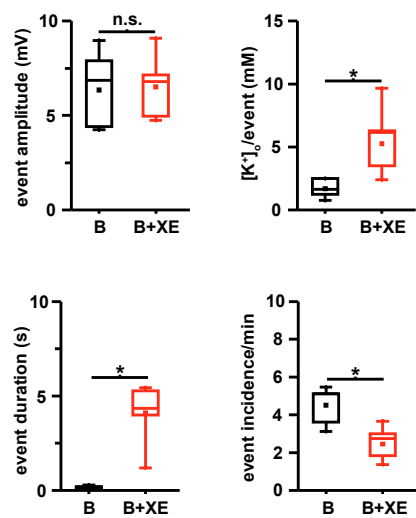

E
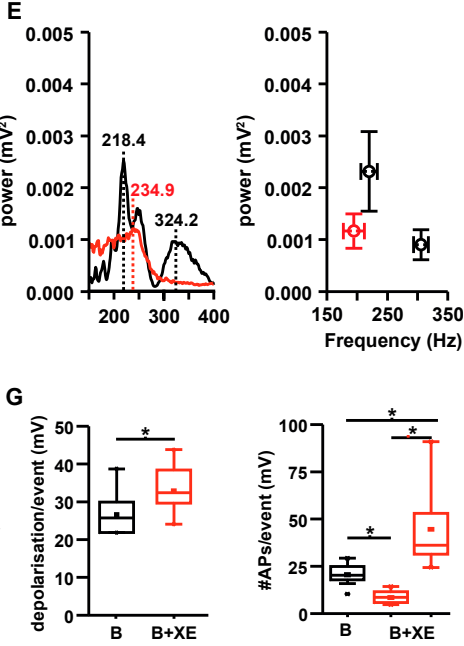

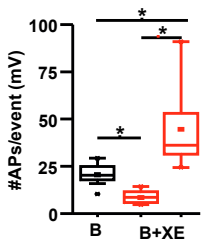

Figure 1. Properties of ILEs and SLEs: (A) Simultaneous recording of field potential (f.p.), extracellular potassium concentration $\left(\left[\mathrm{K}^{+}\right]_{0}\right)$ and intracellular recording from CA3 pyramids (i.c., bottom traces) during interictal-like events (ILEs) induced by bicuculline (black) and seizure-like events (SLEs) induced by the co-application of bicuculline and XE-991 (red); (B) ILEs and SLEs differed significantly in event-associated $\left[\mathrm{K}^{+}\right]_{\mathrm{o}}$-rises, event duration and incidence, while event amplitudes remained unaltered $\left({ }^{*} p<0.05, n=6\right.$, paired $t$-test); (C) Detail of typical f.p. recording and i.c. correlate during ILEs and SLEs. Bicuculline-induced ILEs are short paroxysmal discharges characterized by a slow wave with superimposed high-frequency oscillations (HFOs). The simultaneous i.c., recording shows a typical depolarization with cell firing. SLEs are characterized by an initial ILE followed by repetitive brief bursts. Compared with ILEs, cell firing is reduced during the first component (slow wave) of the discharge with concomitantly increased cell firing during the after discharges; (D) and (E) Fast Fourier transform (FFT)-based frequency sonograms of exemplary ILE and SLE. During bicuculline-induced ILE, HFOs typically displayed two main peaks (see corresponding power spectrum in E, black line). During SLEs, the faster oscillatory peak was abolished (red line). Right: Averaged main frequency and power of HFOs during ILEs (black) and SLEs (red) $(n=6)$; (F) I.c. recording during ILEs (black trace) and SLEs (red trace): bicuculline bursts are marked membrane depolarizations with high frequency action potential (AP)-firing (small black line on top). SLEs also begin with a pronounced membrane depolarization, however, with less firing, followed by repeated cell bursting; and (G) Compared with ILEs (black), SLEs (red) were associated with increased membrane depolarization amplitudes (left). The number of APs decreased significantly during the initial burst under SLEs (red box, middle) compared with ILEs. When the total number of APs during the whole discharge was measured (red box on the right), SLEs were associated with a marked increase in neuronal firing compared with ILEs. $\left({ }^{*} p<0.05\right.$, $n=11$ cells from six slices, paired $t$-test). 
A

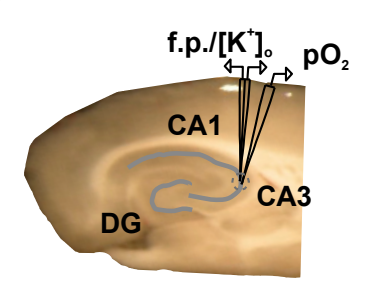

B

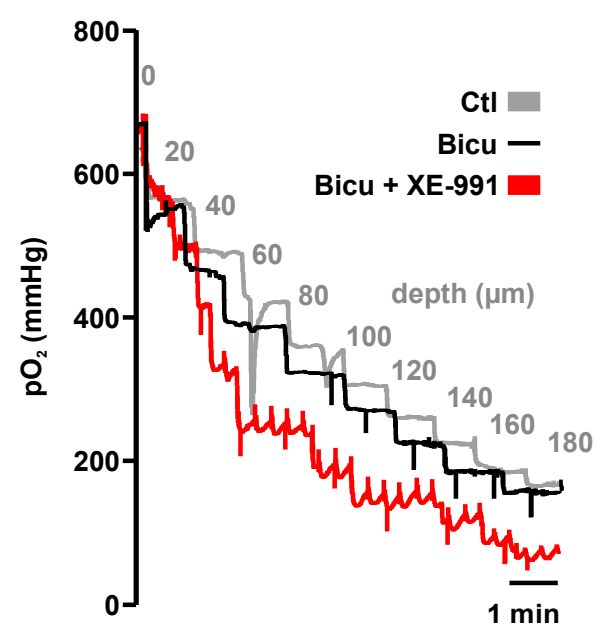

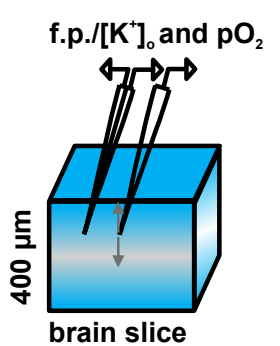

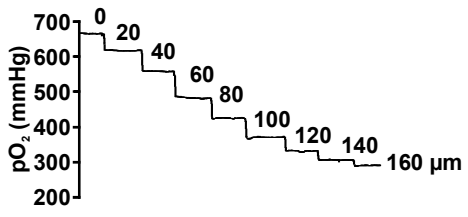

carbogen $=95 \% \mathrm{O}_{2}$ and $5 \% \mathrm{CO}_{2}$

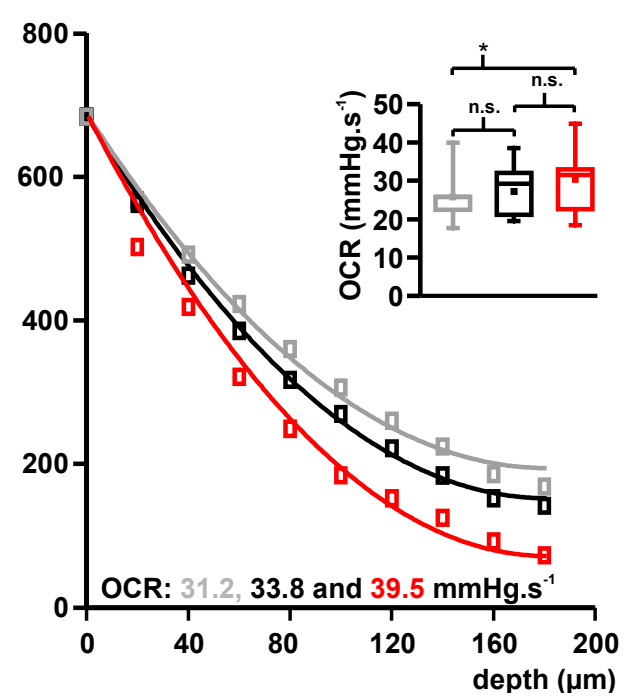

Figure 2. Variations in basal $\mathrm{pO}_{2}$ under bicuculline and bicuculline + XE-991: (A) Left: Picture and scheme of typical electrode placement in acute hippocampal slice. Double-barreled ion-sensitive microelectrodes (with field potential and ion-sensitive recording side) and Clark-style oxygen electrodes were placed $\sim 80 \mu \mathrm{m}$ below the slice surface in the pyramidal layer of area CA3. Acute brain slices receive oxygen from surface and bottom and the partial oxygen pressure $\left(\mathrm{pO}_{2}\right)$ decreases with the distance to the source of oxygen (i.e., distance to the slice bottom and surface) providing typical depth profiles (see right, numbers in trace-distance to slice surface). The oxygen gradient along the slice depends on oxygen supply and solubility, which are both constant under experimental conditions. Hence, changes in $\mathrm{pO}_{2}$ depth profiles reflect activity-dependent $\mathrm{O}_{2}$ consumption; and (B) Using an established reaction-diffusion model, peak $\mathrm{pO}_{2}$-levels at each vertical step in the $\mathrm{pO}_{2}$ profile (left) were fitted (right) to calculate oxygen consumption rates (OCR). OCRs increased from control (spontaneous activity, gray, $31.2 \mathrm{mmHg} \cdot \mathrm{s}^{-1}$ ) to induced ILEs (black, $33.8 \mathrm{mmHg} \cdot \mathrm{s}^{-1}$ ) and SLEs (red, $39.5 \mathrm{mmHg} \cdot \mathrm{s}^{-1}$ ) in this example. The quantitative analysis (inset) revealed a significant OCR increase during SLEs (red) compared with control conditions (gray, ${ }^{*} p=0.008$, n.s. not significant, $n=8$, paired $t$-test with Bonferroni post-hoc correction).

\subsection{Modeling of ATP Consumption Rates and Prediction of FAD Transients for ILEs and SLEs}

Based on OCRs and EAOCRs, we calculated ATP consumption rates and FAD transients using a model of neuronal energy metabolism [19]. Those simulations revealed a $6 \%$ and $32 \%$ increase in basal ATP demand during bicuculline and bicuculline + XE-991 compared with control conditions. Thereby, our calculations revealed a decline in cellular ATP from 3.1 to 3.08 and $3 \mathrm{mM}$ (under bicuculline and bicuculline + XE-991 respectively) and FAD shifting towards a more oxidized state (Figure 4A,B). Single ILEs and SLEs increased ATP demand by 15\% and $94 \%$ compared with control condition (spontaneous activity before bicuculline and/or XE-991 perfusion). Event-associated increase in ATP consumption resulted in a further drop in intracellular ATP content to 3.05 and $2.81 \mathrm{mM}$ for ILEs and SLEs, respectively (Figure 4A). For four FAD containing enzymes (pyruvate dehydrogenase complex, 
$\alpha$-ketoglutarate dehydrogenase complex, mitochondrial glycerol-3-phosphate dehydrogenase and succinate dehydrogenase), simulations predicted higher oxidation peaks and reduction shifts for SLEs than ILEs (Figure 4B). This prediction was verified experimentally by recording FAD autofluorescence of ILEs and SLEs under submerged conditions (Figure 4C). Oxidation peaks increased from median $\mathrm{f} / \mathrm{f}_{0}$ of 1.1\% (P25 0.8, P75 1.7, $n=90$ events; $\mathrm{f}$ - event-associated fluorescence intensity, $\mathrm{f}$-baseline fluorescence intensity) during ILEs to $1.5 \%(1.2,2.0, n=114$ events, $p<0.05$, independent $t$-test; Figure $4 \mathrm{D}$ bottom) for SLEs. Similarly, reduction shifts increased from $-2.2 \%(-2.7,-1.5)$ to $-2.5 \%$ $(-3.3,-2.1, p<0.05$, paired $t$-test). Under submerged conditions (i.e., in the FAD imaging setup) group differences (SLEs vs. ILEs) for event duration, event-associated $\left[\mathrm{K}^{+}\right]_{\mathrm{o}}$ rises and oxygen drops were similar to interface conditions, but ILEs/SLEs were generally shorter (especially SLEs) and smaller in field potential, $\left[\mathrm{K}^{+}\right]_{\mathrm{o}}$ and $\mathrm{pO}_{2}$ amplitudes (Figure $4 \mathrm{D}$ ). In contrast to interface conditions when field potential amplitudes were similar for ILEs and SLEs, under submerged conditions, amplitudes increased from $2.8 \mathrm{mV}(1.3,3.2)$ for ILEs ( half amplitude compared with interface conditions) to $5.3 \mathrm{mV}(2.8,6.5)$ for SLEs (Figure 4D).

A

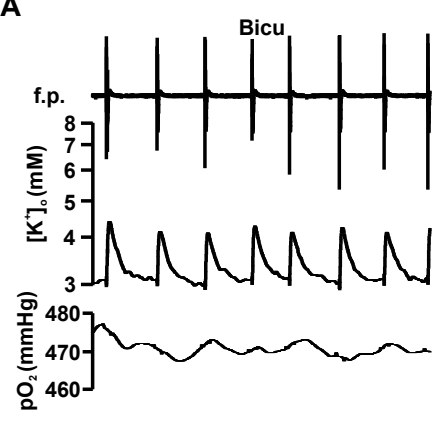

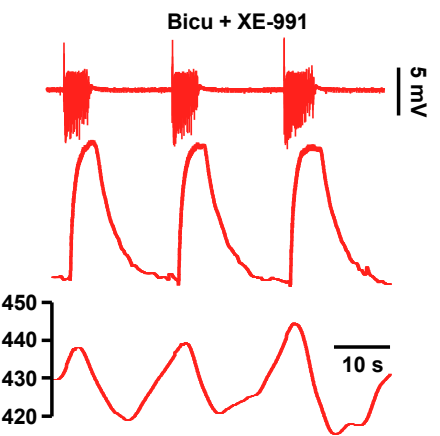

B

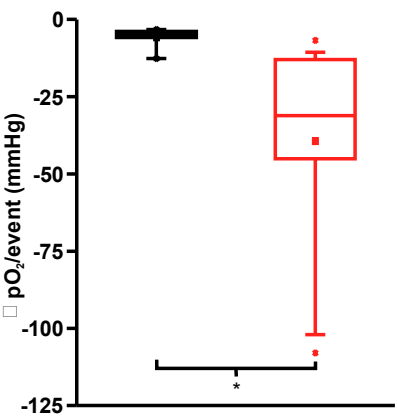

C

D
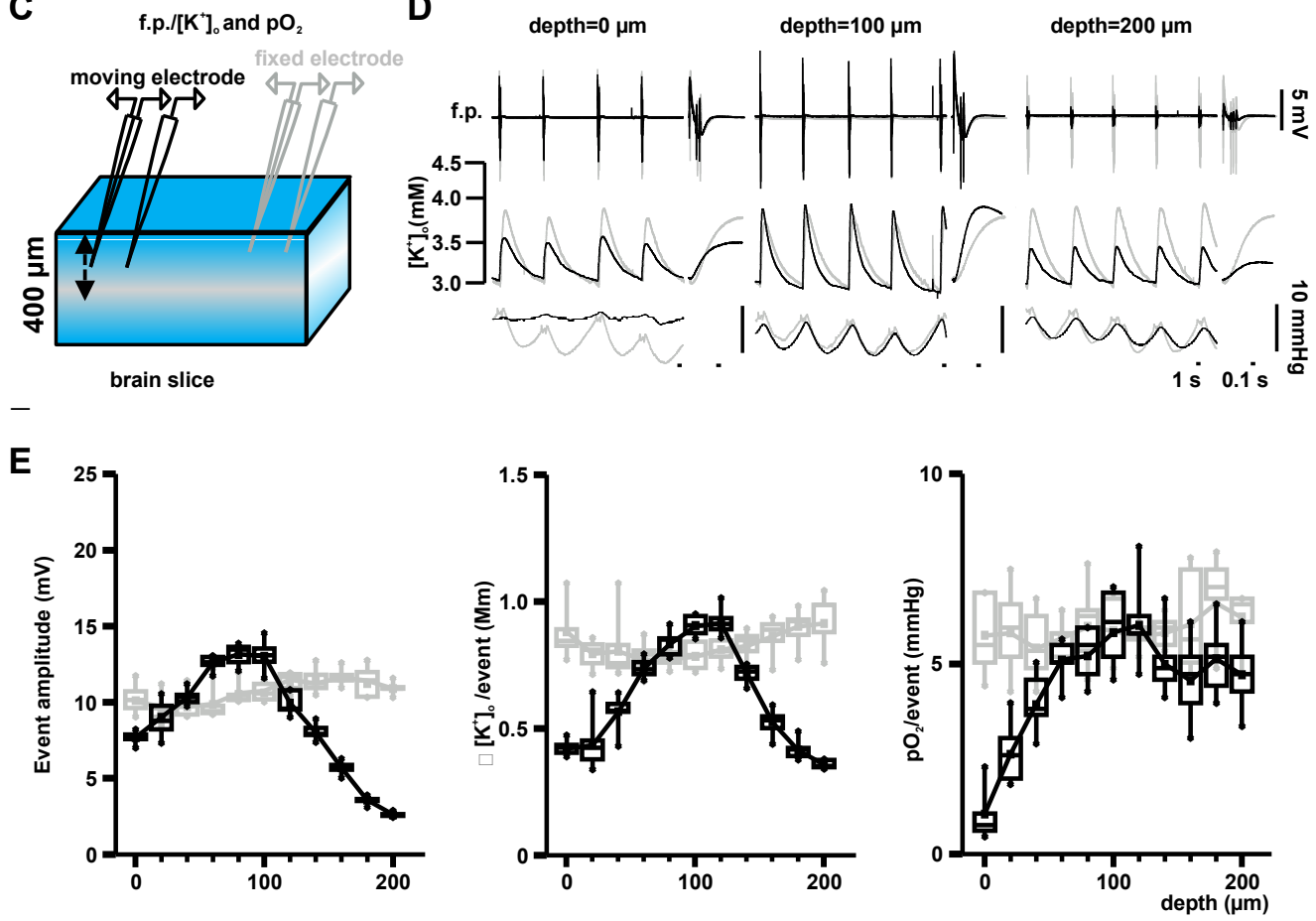

Figure 3. Cont. 

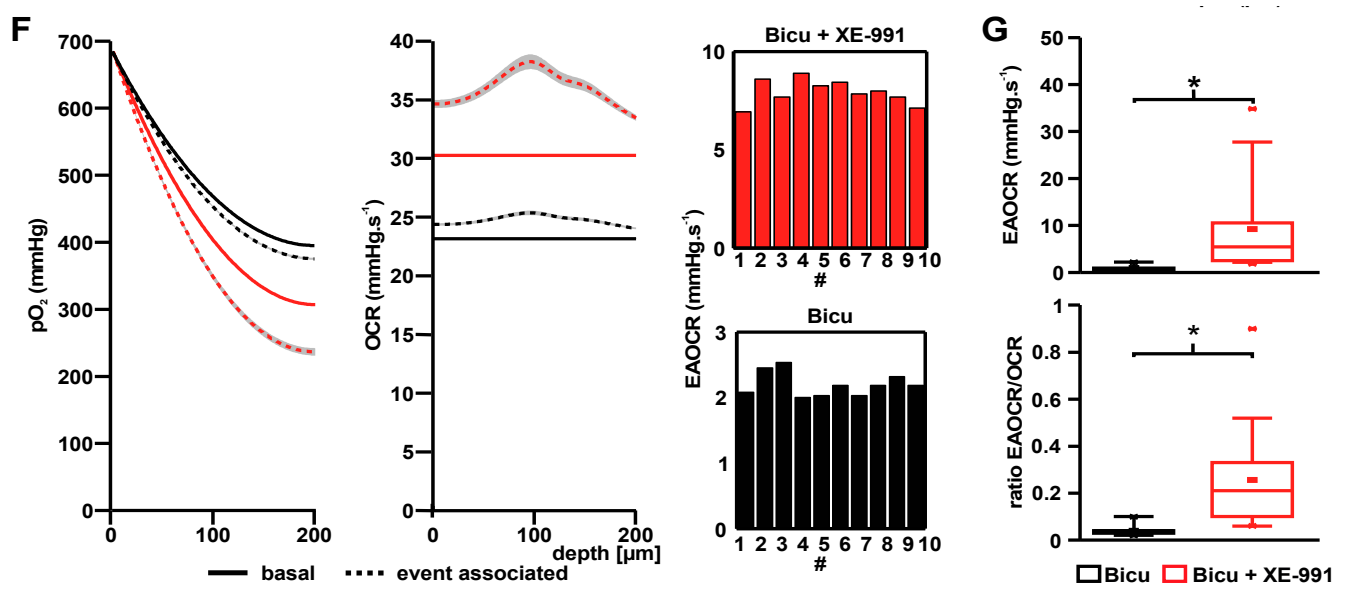

Figure 3. Locality of activity and modeling of local oxygen consumption rates associated with ILEs and SLEs in brain slices: (A) Typical f.p., extracellular potassium $\left(\left[\mathrm{K}^{+}\right]_{\mathrm{o}}\right)$ and oxygen recordings of ILEs (black) and SLEs (red). Event-associated oxygen baseline drops were larger in SLEs compared with ILEs; (B) Local oxygen drops during ILEs and SLEs at $80 \mu \mathrm{m}$ from the slice surface. Event-related $\mathrm{pO}_{2}$ drops during SLEs (red) were significantly larger compared with ILEs (black) $(p=0.011, n=8$ and 15 for ILEs and SLEs respectively, independent $t$-test); (C) Scheme of brain slice recordings under interface conditions with two pairs of double-barreled potassium-sensitive microelectrodes and Clark-style oxygen electrodes. One pair of electrodes was moved in vertical steps through the pyramidal layer in area CA3 (moving electrode). A second stationary pair of electrodes was placed in close vicinity at $\sim 80 \mu \mathrm{m}$ below the slice surface (fixed electrode) to control for signal stability; (D) Overlay of the recording signals from the two pairs of electrodes (black: moving electrode, grey: fixed electrode) during bicuculline-induced ILEs. F.p., $\left[\mathrm{K}^{+}\right]_{\mathrm{o}}$ and oxygen drops remained stable at the fixed electrode, while f.p. amplitudes and $\left[\mathrm{K}^{+}\right]_{\mathrm{o}}$ peaks were larger at $100 \mu \mathrm{m}$ compared with 0 and $200 \mu \mathrm{m}$ at the moving electrode. Oxygen dips increased from 0 to $100 \mu \mathrm{m}$ and remained large at a depth of $200 \mu \mathrm{m}$ in the moving electrode; (E) ILE-associated amplitudes, event-related peak potassium levels and $\mathrm{pO}_{2}$-drops at different depths along the slice. Field potential and potassium levels showed a very similar amplitude distribution with a peak around $100 \mu \mathrm{m}$. Oxygen drops were smaller near the surface, but remained stable after 60-80 $\mu \mathrm{m}$ (gray-fixed electrode, black—-moving electrode); (F) Fitted basal $\mathrm{pO}_{2}$-depth profiles (left, solid line) and event-associated depth profiles (left, dashed line) for bicuculline (black) and bicuculline + XE-991 (red). Basal OCRs (solid line, right graph) and depth-dependent event-associated OCRs (EAOCR, dotted line, right graph, EAOCR $=\mathrm{OCR} /$ event $\left(\mathrm{mmHg} \cdot \mathrm{s}^{-1}\right)$ ). Bar plots show EAOCRs for ten individual events; and (G) EAOCR (top) and ratio of EAOCR to basal OCR (bottom) during ILEs and SLEs. During SLEs (red) EAOCRs were significantly higher compared with EAOCRs during ILEs (black; $p=0.016, n=8$ and 15 for ILEs and SLEs; independent $t$-test). The ratio comparing EAOCRs to the basal OCR was significantly higher under SLEs compared with ILEs $(p=0.035, n=8$ and 15 for ILEs and SLEs, respectively, independent $t$-test). 

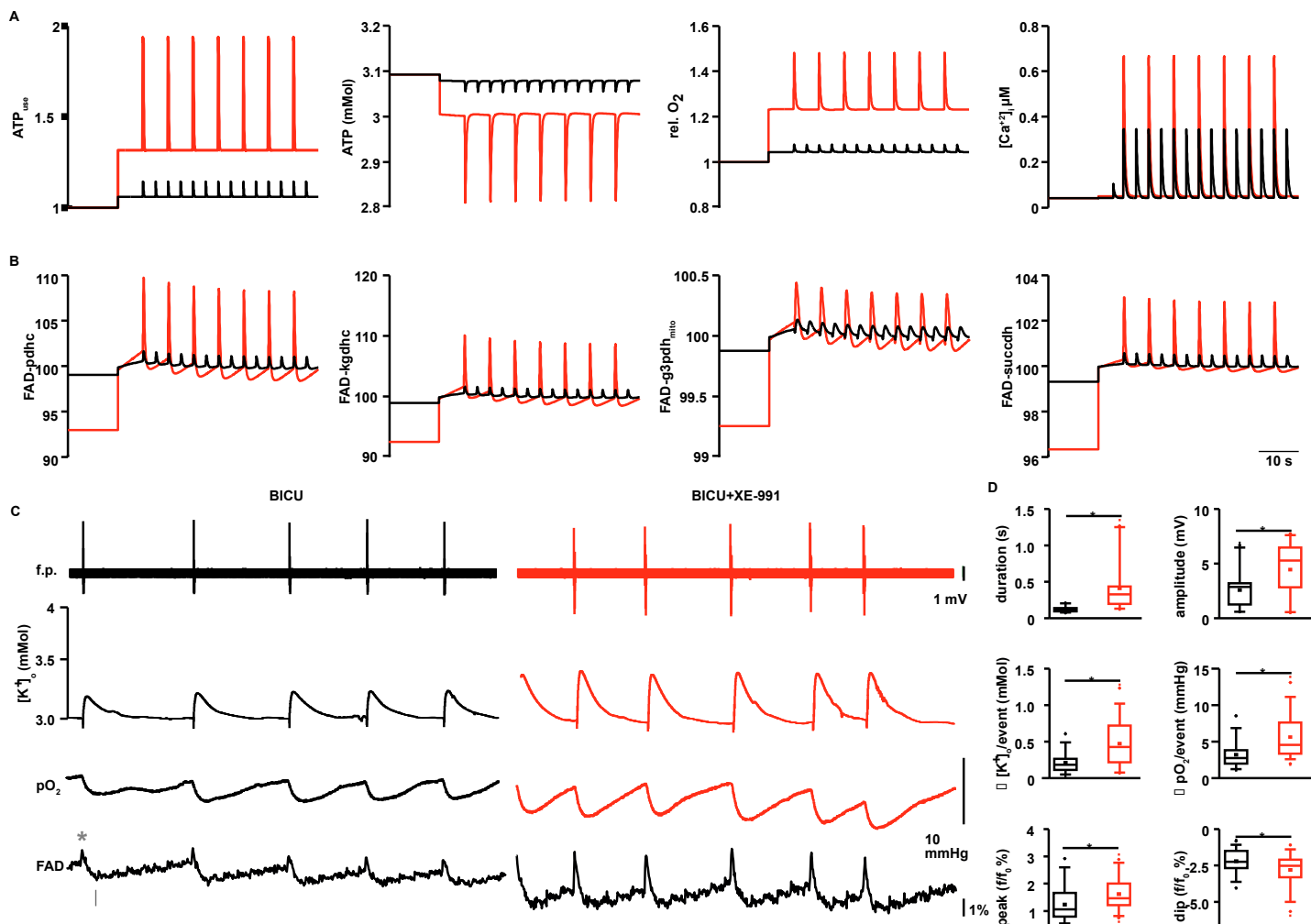

$\overline{5 s}$

$\overline{5 \mathrm{~s}}$
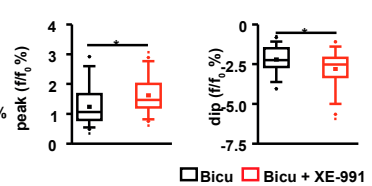

Figure 4. Modeling of basal and event-associated ATP consumption rates, ATP levels and FAD reduction states associated with ILEs and SLEs: (A) Basal ATP consumption increased by $6 \%$ and $32 \%$ compared with control during bicuculline (black) and bicuculline + XE-991 (red) application, which decreased cellular ATP levels to $3.08 \mathrm{mM}$ and $3.0 \mathrm{mM}$. Event associated ATP consumption was higher under SLEs ( $94 \%$ above control) compared with ILEs ( 15\% above control) and associated with a decrease in cellular ATP level to $3.05 \mathrm{mM}$ and $2.81 \mathrm{mM}$. The third plot summarizes the relative changes in basal OCR and EAOCR (see also Figures 2B and 3G). Intracellular $\mathrm{Ca}^{2+}$ transients are shown on the right; (B) FAD reduction states for FAD bound to pyruvate dehydrogenase complex (pdhc), $\alpha$-ketogluterate dehydrogenase complex (kgdhc), mitochondrial glycerol-3-phosphate dehydrogenase $\left(\mathrm{g} 3 \mathrm{pdh} \mathrm{h}_{\text {mito }}\right)$, and succinate dehydrogenase (succdh). Single events elicit increased FAD oxidation in all enzymes, with a higher peak value for SLEs compared with ILEs. In order to emphasize changes in event-associated FAD redox states, ILEs and SLEs were aligned, by manually shifting the baseline; (C) Simultaneous f.p., $\left[\mathrm{K}^{+}\right]_{\mathrm{o}}, \mathrm{pO}_{2}$ and FAD-autofluorescence recording during ILEs (black) and SLEs (red). Under submerged conditions event amplitudes were smaller, yet morphologically similar to interface conditions (Figures 1 and 2). Event duration, $\left[\mathrm{K}^{+}\right]_{\mathrm{o}}$ peaks and local $\mathrm{pO}_{2}$ drops increased during SLEs compared with ILEs. Simultaneously recorded FAD-transients showed increased oxidation, which was predicted by the model. Importantly, the data used for modeling was based on recordings under interface conditions; and (D) Quantification for C. Similar to interface conditions, SLEs showed significantly increased event durations, $\left[\mathrm{K}^{+}\right]_{\mathrm{o}}$-rises and local oxygen drops (top and middle). In contrast with interface conditions, f.p. event amplitudes increased from ILEs to SLEs (top). As predicted by the computational model, event-related FAD-transients, i.e., FAD peaks (see asterisk in C) and dips (see arrow in C), were significantly enhanced (bottom). ${ }^{*} p<0.05, n=90$ individual ILEs and 114 SLEs, independent $t$-test.

\section{Discussion}

We studied metabolic changes and energy demand during pharmacologically induced ILEs and SLEs. We combined multiparametric recordings (field potential, $\left[\mathrm{K}^{+}\right]_{\mathrm{o}}, \mathrm{pO}_{2}$ ) in the acute 
hippocampal slice preparation from adult rats. By implementing $\mathrm{pO}_{2}$ depth profiles in theoretical models, we quantify for the first time basal OCR, EAOCR, ATP consumption, cellular ATP levels and FAD transients for ILEs and SLEs. While bicuculline did not significantly increase basal OCR, adding XE-991 mildly, but significantly, increased basal OCR. The transition from ILEs to SLEs roughly doubled the associated potassium transients, and increased EAOCR and ATP consumption by a factor of $\sim 5$.

It is well known that GABAergic disinhibition induces hypersynchronous activity in hippocampal area CA3 pyramidal neurons (e.g., [20,21]). Blockage of M-currents transforms this ILEs into SLEs [22], an observation first made in the magnesium-free seizure model [23] and confirmed by our recordings. We show that ILEs/SLEs and associated $\left[\mathrm{K}^{+}\right]_{\mathrm{o}}$ changes were maximal in amplitudes at a depth of $\sim 80-100 \mu \mathrm{m}$ (bell-shape) below the slice surface, suggesting a larger number of viable active neurons at this depth under interface conditions. In contrast, oxygen dips grew in amplitude with depth and remained elevated in the slice core despite reduced field potential amplitudes (Figure 3E). Injury during tissue preparation may explain reduced activity at the slice surface. However, in the slice core $(200 \mu \mathrm{m}$ from the surface), where oxygen levels were well above the threshold for failure in ATP production $(40 \mathrm{mmHg}$ ) [1], a clear explanation for the reduced activity is lacking.

In the in vitro slice preparation, oxygen solely distributes by diffusion because it lacks the circulation of blood. Hence, $\mathrm{pO}_{2}$ cannot increase beyond a point of oxygen consumption [24]. Thus, focal oxygen recordings only reveal that oxygen was consumed between its source and the location of the electrode, but not exactly where. This may be of clinical relevance in neurointensive care patients, where cerebral blood flow (i.e., oxygen supply) is often disturbed [25], subsequently increasing the distance from the recording site to the source of oxygen. Oxygen depth-profiles recorded under interface conditions resembled those previously reported for hippocampal slices [26]. Importantly, in contrast with the whole hippocampus preparation [6], we did not observe hypoxic levels in the slice core under interface conditions. Nevertheless, reduced oxygen levels under submerged conditions may explain why ILEs/SLEs were generally shorter and smaller in field potential and $\left[\mathrm{K}^{+}\right]_{\mathrm{o}}$ amplitude compared with interface conditions. Oxygen-dependency (even above the hypoxia threshold) of various activity patterns, including highly energy-demanding gamma oscillation, were previously described [27]. Similarly, redox-states of $\mathrm{NAD}^{+} / \mathrm{NAD}(\mathrm{P}) \mathrm{H}$ and $\mathrm{FAD} / \mathrm{FADH}_{2}$ are affected by oxygen availability. Following electrical stimulation in acute brain slices, the NADH signal is biphasic and shows prominent oxidation peaks (first phase) under 95\% oxygen supply, whereas reduction overshoots (second phase) are larger when oxygen supply is reduced [26,28]. Importantly, in a recent study, FAD autofluorescence mirrored NADH signals (reduced NAD, i.e., NADH is fluorescent) indicating that either FAD or NADH signals can be used likewise [6]. In line with their findings for bicuculline-induced ictal events, we recorded prominent phases of enhanced FAD reduction following brief oxidative peaks for ILEs and SLEs in the submerged imaging setup at $\mathrm{pO}_{2}$ levels of $\sim 100 \mathrm{mmHg}$ [29]. Computed FAD transients based on $\mathrm{pO}_{2}$ recordings under interface conditions at a depth of $100 \mu \mathrm{m}$ (i.e., with greater tissue oxygen levels of $\sim 400 \mathrm{mmHg}$; see Figure $3 \mathrm{~F}$ ), qualitatively predicted recorded FAD signals, thereby validating the model.

Our modelling approach allowed the calculation of OCRs, ATP levels, ATP consumption rates, tricarboxylic acid cycle enzyme activities, and regulatory interdependencies that cannot be obtained directly. The extent of OCR increases during SLEs has never been determined. Kann and colleagues showed in the CA3 region in rat slice cultures a similar decrease in interstitial $\mathrm{pO}_{2}$ during SLEs and gamma oscillations [30]. Here we report that the transformation from interictal to seizure-like events is associated with a ca. five-fold increase in oxygen consumption. Together with the finding of increased $\left[\mathrm{K}^{+}\right]_{\mathrm{o}}$, greater neuronal depolarization and increased AP firing during SLEs, we propose that a major fraction of the additionally consumed oxygen during SLEs goes to $\mathrm{Na}^{+}-\mathrm{K}^{+}$-ATPase-mediated restoration of ion gradients and neurotransmitter reuptake and recycling [31]. Compared with control conditions (before bicuculline and/or XE-991 wash-in) the relative increase in OCR during SLEs is $\sim 44 \%$ compared to an increase of $\sim 8 \%$ during ILEs. This increase of OCR corresponds to an increase in 
ATP demand by $\sim 94 \%$ and $\sim 15 \%$, respectively. This means that oxygen is more efficiently used for ATP production during SLEs than under control conditions. Oxygen is the final electron acceptor in the respiratory chain and the OCR is equivalent to respiratory chain activity. During control conditions the protons pumped by the respiratory chain are used to fuel various mitochondrial processes, e.g., ATP production, ion homeostasis, and heat production. While ATP production accounts for about $60 \%$ of the proton usage under normal conditions [32], the additional protons pumped by the respiratory chain during SLE are used almost exclusively for ATP production thereby increasing the mitochondrial energy production efficiency $\left(\mathrm{ATP} / \mathrm{O}_{2}\right)$. Our simulations further predicted only a moderate drop of cellular ATP levels by $9 \%$ during SLE. This is in agreement with work by Chapman et al. who measured a decrease in cellular ATP levels by $7 \%$ during short-term seizure activity [33]. This should be kept in mind when considering the role of metabolism in regulation of neuronal excitability by ATP-dependent ion channels, e.g., via ATP-sensitive potassium channels. The moderate drop in ATP levels together with the significant increase in OCR reflects the metabolic capacity of the brain to adequately increase its energy production rate during SLEs. Increased $\left[\mathrm{K}^{+}\right]_{\mathrm{o}}$ during ILEs/SLEs despite sufficient ATP supply thus implies that the $\mathrm{Na}^{+}-\mathrm{K}^{+}$-ATPase is operating at maximal velocity, yet is not able to revert massive potassium accumulation in the extracellular space during on-going epileptiform activity. The increase in ATP demand is matched by an increase in tricarboxylic acid cycle activity to produce the NADH used by the increased activity of the respiratory chain. This leads to a shift in mitochondrial redox state and an increase in the oxidized fraction of FAD in all FAD containing dehydrogenases. The return of the FAD reduction state and $\left[\mathrm{K}^{+}\right]_{\mathrm{o}}$ to baseline levels between successive SLEs is an additional indicator that the metabolic capacity is sufficient to meet the immediate demand as no prolonged activity of the dehydrogenases is expected. This, however, does not rule out that these types of epileptiform activity cause cellular injury in vivo. In contrast to our experimental setting where glucose and oxygen were constantly supplied, in patients following stroke or traumatic brain injury, seizures are common and may develop under conditions of impaired neurovascular coupling. Thus, shortages in energy substrates may occur due to reduced cerebral perfusion [25,34-37]. Understanding metabolic demand underlying different brain activity patterns including epileptiform activity may guide therapy, i.e., adjustment of cerebral perfusion pressure which is influenced by arterial blood pressure and the opposing intracranial pressure. In addition, knowledge about metabolic changes induced by epileptiform activity may help to detect seizure onset zones non-invasively with advanced imaging tools, such as magnetic resonance spectroscopy [38,39].

\section{Materials and Methods}

\subsection{Slice Preparation and Maintenance}

For this study, 25 male Wistar rats (weight: $200-250$ g, age: 6-8 weeks) were sacrificed in accordance with the Helsinki declaration and institutional guidelines (LAGeSo Berlin, T0096/02, 2002). Animals were decapitated under anesthesia with isoflurane $(2 \%)$ and laughing gas $\left(\mathrm{N}_{2} \mathrm{O}\right.$, $70 \%$ ). Brains were rapidly removed and transferred to cold and gassed (carbogen, $95 \% \mathrm{O}_{2}$ and $5 \%$ $\mathrm{CO}_{2}$ ) artificial cerebrospinal fluid (aCSF) containing (in $\mathrm{mM}$ ): $129 \mathrm{NaCl}, 21 \mathrm{NaHCO}_{3}, 10$ glucose, $3 \mathrm{KCl}, 1.25 \mathrm{NaH}_{2} \mathrm{PO}_{4}, 1.6 \mathrm{CaCl}_{2}$, and $1.2 \mathrm{MgCl}_{2}$. Osmolarity and $\mathrm{pH}$ were $295-305 \mathrm{mOsm} / \mathrm{L}$ and $7.35-7.45$, respectively. Horizontal hippocampal slices ( $400 \mu \mathrm{m}$ thick) were prepared with a Leica VT $1200 \mathrm{~S}$ vibratome (Leica, Wetzlar, Germany) and stored in an interface chamber with continuous aCSF perfusion (flow rate of $2 \mathrm{~mL} / \mathrm{min}$, temperature $34-35^{\circ} \mathrm{C}$, gassed with carbogen). Experiments started after two hours of recovery following the slicing procedure. For FAD-fluorescence imaging the slices were transferred to a submerged chamber (flow rate $10 \mathrm{~mL} / \mathrm{min}$, temperature ca. $34-35^{\circ} \mathrm{C}$ ) following the recovery period. 


\subsection{Electrophysiology, Oxygen Recordings and Fluorescence Recordings}

All experiments were performed in area CA3 of the hippocampal formation. Simultaneous field potential and extracellular potassium $\left(\left[\mathrm{K}^{+}\right]_{\mathrm{o}}\right)$ measurements were performed using double-barrelled ion-sensitive microelectrodes built according to the protocol of Heinemann and Arens (1992) [40]. The reference side of the electrode was filled with $154 \mathrm{mM} \mathrm{NaCl}$ while the ion sensitive side was filled with $100 \mathrm{mM} \mathrm{KCl}$ and its tip contained potassium ionophore I 60031 (Fluka, Sigma, Buchs, Switzerland). Recorded electrical potentials were converted to potassium concentrations using Nernst's equation as previously described.

Intracellular recordings of CA3 pyramidal cells were performed simultaneously to field potential and $\left[\mathrm{K}^{+}\right]_{\mathrm{o}}$ recordings. We used sharp microelectrodes (resistance 60-90 M $\Omega$ ) filled with $2.5 \mathrm{mM}$ $\mathrm{K}^{+}$-acetate. Event-associated membrane depolarisations were quantified by measuring the maximal membrane depolarisation in between APs.

Basal and event-associated $\mathrm{pO}_{2}$ were measured using Clark-style oxygen sensors (tip: $10 \mu \mathrm{m}$; Unisense, Aarhus, Denmark) placed near the ion-sensitive microelectrode. Oxygen electrodes were polarized for $>12 \mathrm{~h}$ and two point calibrated in aCSF gassed with $50 \%$ and $95 \% \mathrm{O}_{2}$ before each recording session. For depth profiles, the $\mathrm{pO}_{2}$-electrode was fixed to a mechanical manipulator and moved vertically through the slice in steps of $20 \mu \mathrm{m}$ until additional steps no longer reduced $\mathrm{pO}_{2}$ (usually $\sim 200 \mu \mathrm{m}$ below surface). To investigate the locality of neuronal activity along the slices we also performed stepwise measurements of the field potential, $\left[\mathrm{K}^{+}\right]_{\mathrm{o}}$ during ILEs. To exclude general signal changes, we performed this simultaneously with a second pair of electrodes placed at a depth of $80 \mu \mathrm{m}$ (see Figure 3C). FAD ${ }^{+}$(oxidized form) autofluorescence was recorded under submerged conditions using a custom-built imaging setup equipped with a light emitting diode (LED, $460 \mathrm{~nm}$ wavelength), a photomultiplier tube and a X20 submerged objective that was focussed on stratum pyramidale of area CA3 [41]. The LED (Lumen, Prior scientific, Seefelder, Germany) was set at $18 \%$ intensity (Power in focus plane with objective: $2.390 \mathrm{~mW}$ ) and was triggered externally with a Master 8 (A.M.P.I., Jerusalem, Israel). To reduce bleaching and phototoxicity we performed excitation with pulsed light $(5 \mathrm{~ms}, 5 \mathrm{~Hz})[29]$.

\subsection{Drugs}

Epileptiform activity was induced by application of $10 \mu \mathrm{M}$ bicuculline methiodide and subsequent co-application of $10 \mu \mathrm{M}$ XE-991 dihydrochloride (both from Tocris, Bristol, UK).

\subsection{Data Acquisition and Data Analysis}

Analog signals were digitalized with Power1401 and recorded with Spike2 (Cambridge Electronic Design Limited, Cambridge, UK). Data analysis and statistics were performed using Spike2, Origin software (Version 6, Microcal Software, Northampton, MA, USA) and SPSS v.20.0 (IBM Corporation, Armonk, NY, USA). In most of the cases, data is shown in boxplots. Fluorescence is shown as $\Delta \mathrm{f} / \mathrm{f}_{0}$ where $f_{0}$ is the baseline fluorescence intensity. For ILEs and SLEs the lowest value recorded 1 second before the epileptiform discharge was set as 1 . For statistical inference, we performed independent and paired Student's $t$-tests (with Bonferroni correction when necessary) and repeated measures ANOVA. For the number of experiments, " $n$ " refers to the number of slices unless stated differently. Changes were stipulated to be significant for $p<0.05$.

\subsection{Calculation of Basal Oxygen Consumption Rates of Control, Bicuculline and Bicuculline + XE-991 Condition}

Oxygen consumption rates (OCR) were calculated from $\mathrm{pO}_{2}$ depth profiles measured under interface conditions as described in [18]. In short, we applied a reaction-diffusion model for oxygen consisting of diffusive oxygen transport and oxygen consumption within the slice. The slices were divided into layers with equal thickness of $1 \mu \mathrm{m}$. Diffusive distribution of oxygen between the layers is 
described by Fick's Law with a diffusion constant of $1.6 \times 10^{3} \mu \mathrm{m}^{2} / \mathrm{s}$ [18] and oxygen consumption rate within each layer is given by Michaelis-Menten kinetics with a $K_{\mathrm{m}}$-value of $3 \mathrm{mmHg}$ [42]. The OCR was assumed to be homogeneous throughout the slice (i.e., equal in every layer) and is treated as adjustable parameter to match the experimental data. Dirichlet boundary conditions were used at the slice surface and Neumann boundary conditions were used at the $\mathrm{pO}_{2}$ minimum. For paired measurements, $\mathrm{pO}_{2}$ profiles were pruned at the location of the $\mathrm{pO}_{2}$ minimum closest to the slice surface.

\subsection{Calculation of Event Associated Oxygen Consumption During ILEs and SLES}

For the calculation of the OCR associated with ILEs and SLEs (event associated consumption rate, EAOCR) we took into account the locality of the events within the slice, thereby releasing the assumption of homogenous OCR. We assumed that the local OCR is proportional to the activity (magnitude of the event) in each layer of the slice. We fixed the EAOCR associated with a single event by fitting the resulting $\mathrm{pO}_{2}$ values at the position of the electrode to the experimental values.

\subsection{Calculating of FAD Transients and ATP Consumption Rates}

We simulated FAD transients and ATP consumption rates associated with ILEs and SLEs with a metabolic model of neuronal energy metabolism [19]. Using the OCRs obtained from $\mathrm{pO}_{2}$ measurements during bicuculline and bicuculline plus XE-991 under interface conditions and assuming feasible cytosolic calcium transients we determined ATP consumption rates for the different conditions by using the maximal ATP consumption rate as adjustable parameter. We validated the model prediction by comparing the predicted FAD transients with experimental data obtained during the events under submerged conditions. For all simulations we used MATLAB Release2012a (The MathWorks, Inc., Natick, MA, USA) with the optimization tool box.

Acknowledgments: This paper is dedicated to our dear Professor Uwe Heinemann-an unforgettable mentor, colleague and friend! The project was started in his lifetime and as one of the last projects coming from his very lab, it is truly a special contribution for us. We further thank Professor Claudia D. Spies, Professor Jörg RP Geiger and Professor Dietmar Schmitz for their unconditional support and Tanja Specowius for skilled technical assistance. Laboratory facilities and equipment were provided from Charité-Universitätsmedizin Berlin, Neuroscience Research Center and Institute for Neurophysiology; DFG HE 1128/18 to Alon Friedman and Uwe Heinemann, NeuroCure: EXC 257/2 Flexfund to Uwe Heinemann and Jens P. Dreier; DFG grant Ko3814/1-1 to Richard Kovács; DFG grant DR323/5-1 and BMBF Center for Stroke Research 01 EO 0801 to Jens P. Dreier; Agustin Liotta is participant in the BIH Charité Clinician Scientist Program funded by the Charité-Universitätsmedizin Berlin and the Berlin Institute of Health.

Author Contributions: Nikolaus Berndt, Jens P. Dreier, Alon Friedman, Uwe Heinemann, Richard Kovács, Agustin Liotta, and Karl Schoknecht conceived and designed the experiments; Agustin Liotta, Jörg Rösner, and Karl Schoknecht performed the experiments; Nikolaus Berndt, Agustin Liotta, and Karl Schoknecht analysed the data; Nikolaus Berndt contributed computational models; and Nikolaus Berndt, Jens P. Dreier, Alon Friedman, Richard Kovács, Agustin Liotta, and Karl Schoknecht wrote the paper.

Conflicts of Interest: The authors declare no conflict of interest.

\begin{tabular}{ll}
\multicolumn{2}{l}{ Abbreviations } \\
aCSF & Artificial cerebrospinal fluid \\
ATP & Adenosine triphosphate \\
EAOCR & Event-associated oxygen consumption rate \\
FAD & Flavine adenine dinucleotide \\
f.p. & Local field potential \\
GABA & Gama-aminobutyric acid \\
HFO & High frequency oscillation \\
i.c. & Intracellular \\
ILE & Interictal-like event \\
$\mathrm{K}^{+}$ & Potassium ion \\
{$\left[\mathrm{K}^{+}\right]_{\mathrm{o}}$} & Extracellular potassium concentration \\
LED & Light emitting diode
\end{tabular}




$\begin{array}{ll}\mathrm{Na}^{+} & \text {Sodium ion } \\ \mathrm{NADH} & \text { Nicotinamide adenine dinucleotide } \\ \mathrm{OCR} & \text { Oxygen consumption rate } \\ \mathrm{pO}_{2} & \text { Partial oxygen pressure } \\ \mathrm{SLE} & \text { Seizure-like event }\end{array}$

\section{References}

1. Erecińska, M.; Silver, I.A. Tissue oxygen tension and brain sensitivity to hypoxia. Respir. Physiol. 2001, 128, 263-276. [CrossRef]

2. Heinemann, U.; Buchheim, K.; Gabriel, S.; Kann, O.; Kovacs, R. Coupling of electrical and metabolic activity during epileptiform discharges. Epilepsia 2002, 43 (Suppl. S5), 168-173. [CrossRef] [PubMed]

3. Ames, A. CNS energy metabolism as related to function. Brain Res. Rev. 2000, 34, 42-68. [CrossRef]

4. Fisher, R.S.; Scharfman, H.E.; deCurtis, M. How Can We Identify Ictal and Interictal Abnormal Activity? Springer: Berlin, Germany, 2014; pp. 3-23.

5. Fernández-Klett, F.; Offenhauser, N.; Dirnagl, U.; Priller, J. Pericytes in capillaries are contractile in vivo, but arterioles mediate functional hyperemia in the mouse brain. Proc. Natl. Acad. Sci. USA 2010, 107, 22290-22295. [CrossRef] [PubMed]

6. Ivanov, A.I.; Bernard, C.; Turner, D.A. Metabolic responses differentiate between interictal, ictal and persistent epileptiform activity in intact, immature hippocampus in vitro. Neurobiol. Dis. 2015, 75, 1-14. [CrossRef] [PubMed]

7. Pan, J.W.; Williamson, A.; Cavus, I.; Hetherington, H.P.; Zaveri, H.; Petroff, O.A.; Spencer, D.D. Neurometabolism in human epilepsy. Epilepsia 2008, 49, 31-41. [CrossRef] [PubMed]

8. Alavi, A.; Yakir, S.; Newberg, A.B. Positron emission tomography in seizure disorders. Ann. N. Y. Acad. Sci. 2001, 1228, E1-E12. [CrossRef] [PubMed]

9. Heinemann, U.; Buchheim, K.; Gabriel, S.; Kann, O.; Kovacs, R.; Schuchmann, S. Cell death and metabolic activity during epileptiform discharges and status epilepticus in the hippocampus. Prog. Brain Res. 2002, 135, 197-210. [PubMed]

10. Liotta, A.; Caliskan, G.; ul Haq, R.; Hollnagel, J.O.; Rösler, A.; Heinemann, U.; Behrens, C.J. Partial disinhibition is required for transition of stimulus-induced sharp wave-ripple complexes into recurrent epileptiform discharges in rat hippocampal slices. J. Neurophysiol. 2001, 105, 172-187. [CrossRef] [PubMed]

11. Hablitz, J.J.; Heinemann, U. Extracellular $\mathrm{K}^{+}$and $\mathrm{Ca}^{2+}$ changes during epileptiform discharges in the immature rat neocortex. Dev. Brain Res. 1987, 36, 299-303. [CrossRef]

12. Dreier, J.P.; Heinemann, U. Regional and time dependent variations of low $\mathrm{Mg}_{2}{ }^{+}$induced epileptiform activity in rat temporal cortex slices. Exp. Brain Res. 1991, 87, 581-596. [CrossRef] [PubMed]

13. Brown, D.A.; Passmore, G.M. Neural KCNQ (Kv7) channels. Br. J. Pharmacol. 2009, 156, 1185-1195. [CrossRef] [PubMed]

14. Miceli, F.; Soldovieri, M.V.; Ambrosino, P.; Barrese, V.; Migliore, M.; Cilio, M.R.; Taglialatela, M. Genotype-phenotype correlations in neonatal epilepsies caused by mutations in the voltage sensor of K(v)7.2 potassium channel subunits. Proc. Natl. Acad. Sci. USA 2013, 110, 4386-4391. [CrossRef] [PubMed]

15. Soldovieri, M.V.; Boutry-Kryza, N.; Milh, M.; Doummar, D.; Heron, B.; Bourel, E.; Auvin, S. Novel KCNQ2 and KCNQ3 mutations in a large, cohort of families with benign, neonatal epilepsy: First evidence for an altered channel regulation by syntaxin-1A. Hum. Mutat. 2014, 35, 356-367. [CrossRef] [PubMed]

16. Angamo, E.A.; Rösner, J.; Liotta, A.; Kovács, R.; Heinemann, U. A neuronal lactate uptake inhibitor slows recovery of extracellular ion concentration changes in the hippocampal CA3 region by affecting energy metabolism. J. Neurophysiol. 2016, 116, 2420-2430. [CrossRef] [PubMed]

17. Shuttleworth, C.W. Use of $\mathrm{NAD}(\mathrm{P}) \mathrm{H}$ and flavoprotein autofluorescence transients to probe neuron and astrocyte responses to synaptic activation. Neurochem. Int. 2010, 56, 379-386. [CrossRef] [PubMed]

18. Huchzermeyer, C.; Berndt, N.; Holzhütter, H.-G.; Kann, O. Oxygen consumption rates during three different neuronal activity states in the hippocampal CA3 network. J. Cereb. Blood Flow Metab. 2013, 33, 263-271. [CrossRef] [PubMed] 
19. Berndt, N.; Kann, O.; Holzhütter, H.-G. Physiology-based kinetic modeling of neuronal energy metabolism unravels the molecular basis of NAD(P)H fluorescence transients. J. Cereb. Blood Flow Metab. 2015, 35, 1494-1506. [CrossRef] [PubMed]

20. Scharfman, H.E. Synchronization of area CA3 hippocampal pyramidal cells and non-granule cells of the dentate gyrus in bicuculline-treated rat hippocampal slices. Neuroscience 1994, 59, 245-257. [CrossRef]

21. Wong, R.K.; Traub, R.D. Synchronized burst discharge in disinhibited hippocampal slice. I. Initiation in CA2-CA3 region. J. Neurophysiol. 1983, 49, 442-458. [PubMed]

22. Treven, M.; Koenig, X.; Assadpour, E.; Gantumur, E.; Meyer, C.; Hilber, K.; Kubista, H. The anticonvulsant retigabine is a subtype selective modulator of GABA A receptors. Epilepsia 2015, 56, 647-657. [CrossRef] [PubMed]

23. Qiu, C.; Johnson, B.N.; Tallent, M.K. $\mathrm{K}^{+} \mathrm{M}$-Current regulates the transition to seizures in immature and adult hippocampus. Epilepsia 2007, 48, 2047-2058. [CrossRef] [PubMed]

24. Masamoto, K.; Tanishita, K. Oxygen transport in brain tissue. J. Biomech. Eng. 2009, 131, 74002. [CrossRef] [PubMed]

25. Dreier, J.P. The role of spreading depression, spreading depolarization and spreading ischemia in neurological disease. Nat. Med. 2001, 17, 439-447. [CrossRef] [PubMed]

26. Foster, K.A.; Beaver, C.J.; Turner, D.A. Interaction between tissue oxygen tension and NADH imaging during synaptic stimulation and hypoxia in rat hippocampal slices. Neuroscience 2005, 132, 645-657. [CrossRef] [PubMed]

27. Hájos, N.; Ellender, T.J.; Zemankovics, R.; Mann, E.O.; Exley, R.; Cragg, S.J.; Paulsen, O. Maintaining network activity in submerged hippocampal slices: Importance of oxygen supply. Eur. J. Neurosci. 2009, 29, 319-327. [CrossRef] [PubMed]

28. Galeffi, F.; Somjen, G.G.; Foster, K.A.; Turner, D.A. Simultaneous monitoring of tissue PO2 and NADH fluorescence during synaptic stimulation and spreading depression reveals a transient dissociation between oxygen utilization and mitochondrial redox state in rat hippocampal slices. J. Cereb. Blood Flow Metab. 2011, 31, 626-639. [CrossRef] [PubMed]

29. Rösner, J.; Liotta, A.; Angamo, E.A.; Spies, C.; Heinemann, U.; Kovács, R. Minimizing photodecomposition of flavin adenine dinucleotide fluorescence by the use of pulsed LEDs. J. Microsc. 2016, 264, 215-223. [CrossRef] [PubMed]

30. Kann, O.; Huchzermeyer, C.; Kovács, R.; Wirtz, S.; Schuelke, M. Gamma oscillations in the hippocampus require high complex I gene expression and strong functional performance of mitochondria. Brain 2001, 134, 345-358. [CrossRef] [PubMed]

31. Liotta, A.; Rösner, J.; Huchzermeyer, C.; Wojtowicz, A.; Kann, O.; Schmitz, D.; Kovács, R. Energy demand of synaptic transmission at the hippocampal Schaffer-collateral synapse. J. Cereb. Blood Flow Metab. 2012, 32, 2076-2083. [CrossRef] [PubMed]

32. Berndt, N.; Bulik, S.; Holzhütter, H.-G. Kinetic modeling of the mitochondrial energy metabolism of neuronal cells: The impact of reduced $\alpha$-ketoglutarate dehydrogenase activities on ATP production and generation of reactive oxygen species. Int. J. Cell Biol. 2012, 2012, 1-11. [CrossRef] [PubMed]

33. Chapman, A.G.; Meldrum, B.S.; Siesiö, B.K. Cerebral metabolic changes during prolonged epileptic seizures in rats. J. Neurochem. 1977, 28, 1025-1035. [CrossRef] [PubMed]

34. Hinzman, J.M.; Andaluz, N.; Shutter, L.A.; Okonkwo, D.O.; Pahl, C.; Strong, A.J.; Hartings, J.A. Inverse neurovascular coupling to cortical spreading depolarizations in severe brain trauma. Brain 2014, 137, 2960-2972. [CrossRef] [PubMed]

35. Winkler, M.K.L.; Chassidim, Y.; Lublinsky, S.; Revankar, G.S.; Major, S.; Kang, E.J.; Friedman, A. Impaired neurovascular coupling to ictal epileptic activity and spreading depolarization in a patient with subarachnoid hemorrhage: Possible link to blood-brain barrier dysfunction. Epilepsia 2012, 53, 22-30. [CrossRef] [PubMed]

36. Lowenstein, D.H. Epilepsy after head injury: An overview. Epilepsia 2009, 50, 4-9. [CrossRef] [PubMed]

37. Herman, S.T. Early poststroke seizures: Is it time for prospective treatment trials? Neurology 2011, 77, 1776-1778. [CrossRef] [PubMed]

38. Pan, J.W.; Kuzniecky, R.I. Utility of magnetic resonance spectroscopic imaging for human epilepsy. Quant. Imaging Med. Surg. 2015, 5, 313-322. [PubMed] 
39. Xu, M.Y.; Ergene, E.; Zagardo, M.; Tracy, P.T.; Wang, H.; Liu, W.; Machens, N.A. Proton MR spectroscopy in patients with structural MRI-negative temporal lobe epilepsy. J. Neuroimaging 2015, 25, 1030-1037. [CrossRef] [PubMed]

40. Heinemann, U.; Arens, J. Production and Calibration of Ion-Sensitive Microelectrodes. In Practical Electrophysiological Methods; Kettenmann, H., Grantyn, R., Eds.; Wiley: New York, NY, USA, 1992; pp. $206-212$.

41. Rösner, J.; Liotta, A.; Schmitz, D.; Heinemann, U.; Kovács, R. A LED-based method for monitoring NAD(P)H and FAD fluorescence in cell cultures and brain slices. J. Neurosci. Methods 2013, 212, 222-227. [CrossRef] [PubMed]

42. Kasischke, K.A.; Lambert, E.M.; Panepento, B.; Sun, A.; Gelbard, H.A.; Burgess, R.W. Two-photon NADH imaging exposes boundaries of oxygen diffusion in cortical vascular supply regions. J. Cereb. Blood Flow Metab. 2011, 31, 68-81. [CrossRef] [PubMed]

(C) 2017 by the authors. Licensee MDPI, Basel, Switzerland. This article is an open access article distributed under the terms and conditions of the Creative Commons Attribution (CC BY) license (http://creativecommons.org/licenses/by/4.0/). 